\title{
Comparative Studies of 193-nm \\ Photodissociation and TOF-TOFMS Analysis \\ of Bradykinin Analogues: The Effects of Charge Site(s) and Fragmentation Timescales
}

\author{
Joseph W. Morgan and David H. Russell \\ Laboratory for Biological Mass Spectrometry, Department of Chemistry, Texas A and M University, \\ College Station, Texas, USA
}

\begin{abstract}
The dissociation reactions of $[\mathrm{M}+\mathrm{H}]^{+},[\mathrm{M}+\mathrm{Na}]^{+}$, and $[\mathrm{M}+\mathrm{Cu}]^{+}$ions of bradykinin (amino acid sequence RPPGFSPFR) and three bradykinin analogues (RPPGF, RPPGFSPF, PPGFSPFR) are examined by using 193-nm photodissociation and post-source decay (PSD) TOF-TOF-MS techniques. The photodissociation apparatus is equipped with a biased activation cell, which allows us to detect fragment ions that are formed by dissociation of short-lived $(<1 \mu \mathrm{s})$ photo-excited ions. In our previously reported photodissociation studies, the fragment ions were formed from ions dissociating with lifetimes that exceeded $10 \mu \mathrm{s}$; thus these earlier photofragment ion spectra and post-source decay (PSD) spectra [composite of both metastable ion (MI) and collision-induced dissociation (CID)] were quite similar. On the other hand, short-lived photo-excited ions dissociate by simple bond cleavage reactions and other high-energy dissociation channels. We also show that product ion types and abundances vary with the location of the charge on the peptide ion. For example, $\mathrm{H}^{+}$and $\mathrm{Na}^{+}$cations can bind to multiple polar functional groups (basic amino acid side chains) of the peptide, whereas $\mathrm{Cu}^{+}$ ions preferentially bind to the guanidino group of the arginine side-chain and the N-terminal amine group. Furthermore, when $\mathrm{Cu}^{+}$is the charge carrier, the abundances of non-sequence informative ions, especially loss of small neutral molecules $\left(\mathrm{H}_{2} \mathrm{O}\right.$ and $\left.\mathrm{NH}_{3}\right)$ is decreased for both photofragment ion and PSD spectra relative to that observed for $[\mathrm{M}+\mathrm{H}]^{+}$and $[\mathrm{M}+$ $\mathrm{Na}^{+}$peptide ions. (J Am Soc Mass Spectrom 2006, 17, 721-729) (c) 2006 American Society for Mass Spectrometry
\end{abstract}

$\mathrm{M}$ atrix-assisted laser desorption/ionization (MALDI) [1, 2] and electrospray ionization (ESI) [3] have revolutionized the analysis of biomolecules by mass spectrometry (MS) techniques. Identification of proteins by using "bottom-up" MS techniques, i.e., enzymatic digestion of proteins or protein mixtures followed by peptide mass fingerprinting and database searching $[4,5]$, is now routine, and de novo sequencing [6] and determination of post-translational modifications using tandem mass spectrometry techniques is now commonly practiced in many laboratories. The major factor that complicates peptide structure determination is that the types of fragment ions observed in a tandem mass spectrum are related to the intrinsic properties of the gas-phase peptide ion [7], the activation method used, and the timeframe for probing unimolecular dissociation products $[8,9]$. For example, utilizing only the internal energy acquired during desorption/ionization and a relatively long

Published online March 15, 2006

Address reprint requests to Dr. D. H. Russell, Department of Chemistry, Texas A and M University, 3255 TAMU, College Station TX 77843-3255, USA. E-mail: russell@mail.chem.tamu.edu fragmentation timescale $[\sim 10 \mu \mathrm{s}$, as in post-source decay (PSD) experiments] favors product ions formed via the lowest energy channels [10], i.e., $b_{i}$ - and $y_{i}$-type fragments $[11,12]$. As we showed previously, the observed fragment ions and their relative abundances change significantly if the timescale of the experiment is altered [13].

Collisional activation of gas-phase peptide ions with a neutral gas (eV to several $\mathrm{keV}$ collision energies) can be employed to increase the internal energy of the ions and, thereby, enhance the abundances of sequence informative fragment ions; however, the resulting spectra also contain large numbers of non-sequence informative fragment ions, such as internal cleavage products and ions formed by loss of small neutrals. The presence of these ions complicates primary structure elucidation and reduces sensitivity in sequence informative fragmentation channels. For a discussion of the salient issues, see the recent review by Gabelica and De Pauw [14]. Increasing the collision energy leads to a greater abundance of sequence informative species [15] (e.g., $\mathrm{a}_{\mathrm{i}^{-}}, \mathrm{c}_{\mathrm{i}^{-}}, \mathrm{x}_{\mathrm{i}^{-}}, \mathrm{w}_{\mathrm{ia}^{-}}, \mathrm{d}_{\mathrm{ia}}{ }^{-}$type ions) by permitting faster unimolecular decomposition channels to be accessed [16], but an increase in collision energy does not elim- 
inate contributions from secondary cleavage processes. Additionally, kinetic energy loss [17], which occurs due to inelastic processes involved in conversion of kinetic energy into internal energy modes, reduces mass resolution and mass measurement accuracy for time-offlight (TOF) measurements.

In spite of rapid advances made in tandem MS techniques and increased understanding of peptide ion fragmentation chemistry, there remains substantial interest in developing methods to increase the efficiency and information content of MS-MS spectra. For the past several years we have focused our efforts on two general approaches: (1) 193-nm photodissociation and (2) varying the charge site of peptide ions by using a cationizing reagent with high affinity for specific amino acids. Peptide ions are intrinsic natural chromophores for vacuum ultraviolet radiation (e.g., 157-nm or 193$\mathrm{nm})$, absorbing photons at the amide bonds and the aromatic amino acid side chains [18-20]. In contrast to collisional activation, photon absorption produces an electronically-excited ion, which rapidly undergoes internal conversion to produce a ro-vibronically-excited ion that then dissociates, i.e., dissociation occurs via a vibrational predissociation mechanism. As demonstrated by our previous studies [21-24], 193-nm ArF excimer laser irradiation provides sufficient energy (6.43 eV per photon) to cause prompt fragmentation (i.e., lifetime of the dissociating ion less than $1.0 \mu \mathrm{s}$ ), resulting in sequence ions of type $a_{i}$ and side-chain specific fragment ions $\mathrm{d}_{\mathrm{ia}}, \mathrm{v}_{\mathrm{i}}$, and $\mathrm{w}_{\mathrm{ia}}$. Reilly and coworkers $[25,26]$ recently reported similar photofragmentation of peptide ions using a $157-\mathrm{nm} \mathrm{F}_{2}$ excimer laser. They reported that complete sequence coverage was observed in the form of $\mathrm{x}_{\mathrm{i}}$-type ions for peptides containing a single, $\mathrm{C}$-terminal arginine and $\mathrm{a}_{\mathrm{i}}$-type ions for peptides containing an N-terminal arginine, and they also observed abundant side-chain cleavage product ions.

In this report, we also examine the effect of charge carrier as well as timescale on dissociation reactions. Tomer et al. suggested that localization of charge on peptide $[\mathrm{M}+\mathrm{Na}]^{+}$ions increases the abundances of charge-remote internal fragment ions [27], Cerda et al. [28], and Teesch and Adams [29] suggested that $\mathrm{Na}^{+}$ most strongly interacts with carbonyl oxygen atoms along the peptide backbone to produce primarily $\mathrm{N}$ terminal fragment ions. Bluhm et al. performed extensive studies, including calculations of $\mathrm{Cu}^{+}$binding energies to specific functional groups and amino acid side chains [30], and suggested that $\mathrm{Cu}^{+}$binds most strongly to basic amino acid side chains (i.e., arginine, lysine, and histidine) and to the $\mathrm{N}$-terminus. Although Shields et al. suggested that the metal ion is nonmobile [31], they proposed that charge can be delocalized over the entire molecule by migration of the $\mathrm{H}^{+}$formed as a result of $\mathrm{Cu}^{+}$chelation by $\mathrm{N}$-donor bases. That is, the interaction of $\mathrm{N}$-bases with $\mathrm{Cu}^{+}$increases the acidity of the $\mathrm{H}$-atom bound to the amide nitrogen, which results in deprotonation and migration of the $\mathrm{H}^{+}$ion.
Our previous photodissociation experiments were performed on a homebuilt reflectron-TOF instrument [21] using the PSD focusing method [32] to analyze photofragment ions. Important disadvantages of the PSD focusing technique include (1) metastable ions formed in the first field free drift region are activated by the photodissociation laser resulting in secondary fragments ions [33, 34], and (2) previously reported photofragment ion spectra also contain metastable ion decay products $\left(b_{i}-\right.$ and $y_{i}$-type ions along with small neutral loss ions) owing to the large time interval $(10 \mu \mathrm{s})$ for fragmentation before mass analysis of product ions.

\section{Experimental}

The tandem TOF photodissociation apparatus (Figure 1) consists of a delayed extraction MALDI ion source, a linear TOF-1, and reflectron TOF-2 that has been described previously [22]. The instrument was modified by adding a four-grid decelerating/accelerating photodissociation cell $(10 \mathrm{~cm}$ long) just after the timed-ion selector (TIS). The experiments reported herein were performed using a $15-\mathrm{kV}$ source acceleration potential and an $8-\mathrm{kV}$ potential applied to the photodissociation cell. The field-free drift regions of TOF-1 and TOF-2 are held at ground potential. To acquire a photofragment ion spectrum, the reflectron potential is tuned for a temporal focal point at the photodissociation window for maximum resolution of photofragment ion signal.

Mass-selected ions are decelerated to $7 \mathrm{keV}$ of translational energy as they pass the first two grids of the photodissociation cell. Ions are then irradiated at the center of the cell with a 17-ns pulse from the 193-nm ArF excimer laser (Lambda Physik, LPX100i). Some fraction of the photo-activated ions dissociate before entering the accelerating electric field created by the third and fourth photodissociation cell grids. The timescale of "in-cell" or "prompt" fragmentation is $\sim 1 \mu \mathrm{s}$ for an ion of mass-to-charge $(\mathrm{m} / \mathrm{z})$ 1000, which corresponds to a unimolecular dissociation constant of $\mathrm{k}(\mathrm{E})$ $=10^{6} \mathrm{~s}^{-1}$. Ions are mass-analyzed by TOF- 2 and detected using a dual microchannel plate detector (Burle, Advanced TOF, Sturbridge, MA). Mass spectra are recorded and summed using a digital storage oscilloscope (LeCroy, LC574AM, Chestnut Ridge, NY).

Before acceleration into TOF-2, precursor and fragment ions travel with the same velocities. Since kinetic energy is directly proportional to $\mathrm{m} / \mathrm{z}$, the kinetic energy of a fragment ion within the cell is equal to the product of the parent ion kinetic energy and the ratio of fragment ion $\left(\mathrm{m}_{\mathrm{f}}\right)$ to parent ion $\left(\mathrm{m}_{\mathrm{p}}\right) \mathrm{m} / \mathrm{z}$ values. Kinetic energies for fragment ions after acceleration into TOF-2 are obtained through kinematic analysis and are used to derive an expression for time-of-flight (eq 1).

$$
\text { TOF }=a\left(\frac{m_{f}}{b m_{f}+c}\right)^{\frac{1}{2}}+t_{0}
$$




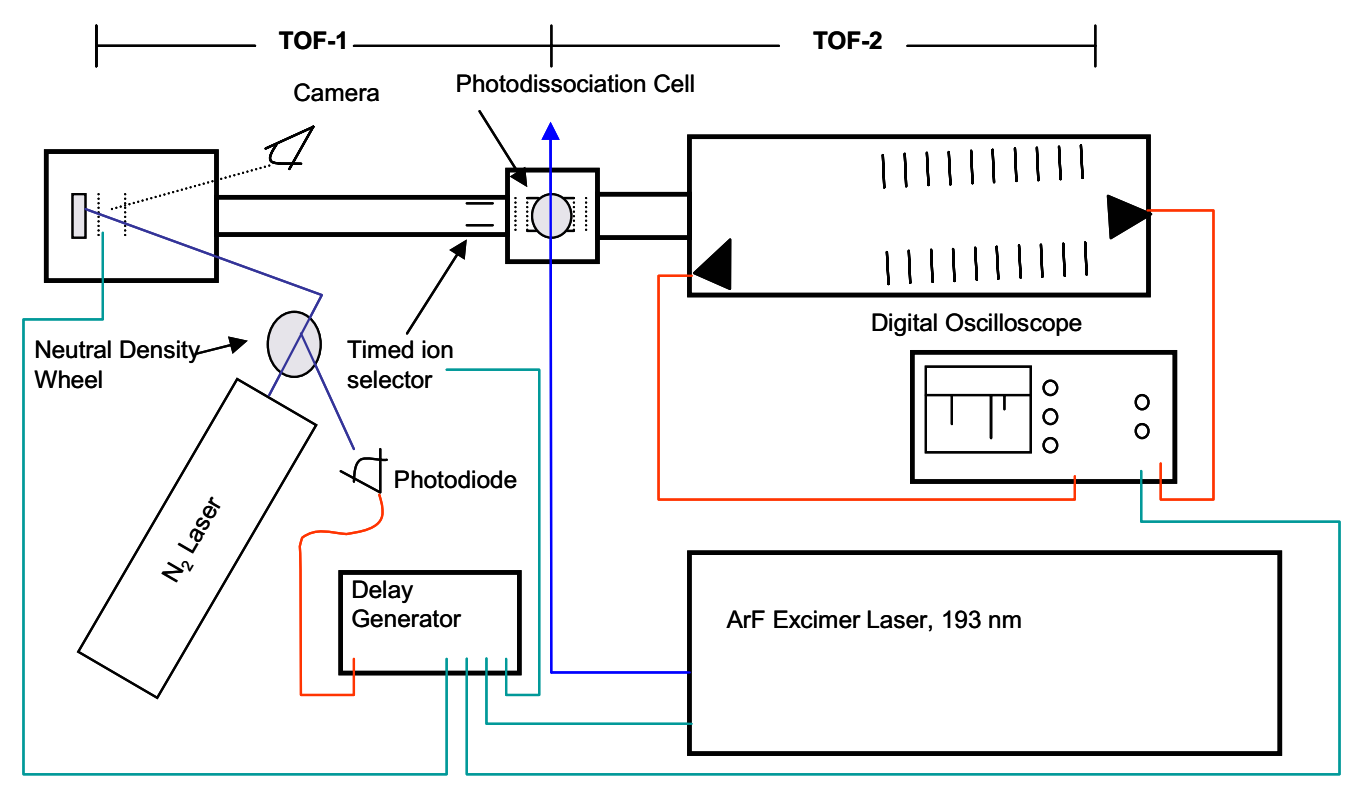

Figure 1. MALDI photodissociation TOF-TOF mass spectrometer.

Parameters (a) and (c) are constant for given source, cell, and reflectron voltages. Parameter $(b)$ is inversely proportional to $\mathrm{m}_{\mathrm{p}}$, and the intercept $\left(t_{0}\right)$ is directly proportional to the square root of $\mathrm{m}_{\mathrm{p}}$. Photofragment ion TOF data is downloaded from the oscilloscope and converted to an x-y list format using Galactic Grams/ 386 Spectral Conversion tool. Calibration is applied before plotting volts of signal versus $\mathrm{m} / \mathrm{z}$ using SigmaPlot software (SPSS Inc., Chicago, IL).

Post-source decay (PSD) spectra were acquired using the Applied Biosystems 4700 Proteomics Analyzer (Framingham, MA) using collisional cell pressures set for "medium" and 1-keV collision energies. PSD data were exported in ASCII $x-y$ format using the Applied Biosystems Data Explorer software, then plotted using SigmaPlot.

PSD spectra are composed of post-source decay fragment ions resulting from metastable ion and CID processes [35]. We previously showed that it is important to minimize the contributions of PSD ions to the photofragment ion spectrum. For example, we previously showed that binary matrices of CHCA and fructose can be used to lower the internal energy of MALDI- formed ions [23]; however, in some cases fructose causes a reduction in peptide ion signal, especially for $[\mathrm{M}+\mathrm{Cu}]^{+}$ions and for some $[\mathrm{M}+\mathrm{H}]^{+}$ions. The photofragment ion spectra reported herein were acquired using a single component matrix and to reduce the abundances of PSD ions the ionization laser power was maintained at threshold. The biased activation cell also greatly reduces contributions from PSD fragment ions, because the length of the cell is only a small fraction of the total ion flight path. In addition, low $\mathrm{m} / \mathrm{z}$ PSD fragment ions are rejected by the decelerating field at the entrance to the photodissociation cell. In a recent paper we showed that few PSD fragment ions are detected in the "laser off" spectrum [34].

All peptide samples (Table 1) and cupric sulfate were obtained from Sigma-Aldrich (St. Louis, MO). Sodium carbonate was obtained from EM Science (Gibbstown, $\mathrm{NJ}$ ), and $\alpha$-cyano-4-hydroxycinnamic acid (CHCA) was obtained from Aldrich Chemical (Milwaukee, WI). All peptides and reagents were used without further purification. Stock solutions of the peptides were prepared at a concentration of $50 \mu \mathrm{g} / \mathrm{mL}$ in distilled deionized water. For analysis of protonated peptides, the stock

Table 1. Bradykinin analogues

Theoretical monoisotopic $\mathrm{m} / \mathrm{z}$

\begin{tabular}{llrrr}
\multicolumn{1}{c}{ Peptide } & Sequence & {$[\mathrm{M}+\mathrm{H}]^{+}$} & {$[\mathrm{M}+\mathrm{Na}]^{+}$} & 595.3 \\
\hline \hline Bradykinin Fragment 1-5 & RPPGF & 573.3 & 682.3 & 635.2 \\
Bradykinin Fragment 1-6 & RPPGFS & 660.3 & 779.4 & 722.3 \\
Bradykinin Fragment 1-7 & RPPGFSP & 757.4 & 623.3 & 819.3 \\
Bradykinin Fragment 2-7 & PPGFSP & 601.3 & 926.5 & 663.2 \\
Bradykinin Fragment 1-8 & RPPGFSPF & 904.5 & 926.5 & 966.4 \\
Bradykinin Fragment 2-9 & PPGFSPFR & 904.5 & 1054.5 & 1096.4 \\
Lys ${ }^{1}$-Bradykinin & KPPGFSPFR & 1032.6 & 1082.5 & 1122.5 \\
Bradykinin & RPPGFSPFR & 1060.6 & \\
\hline
\end{tabular}



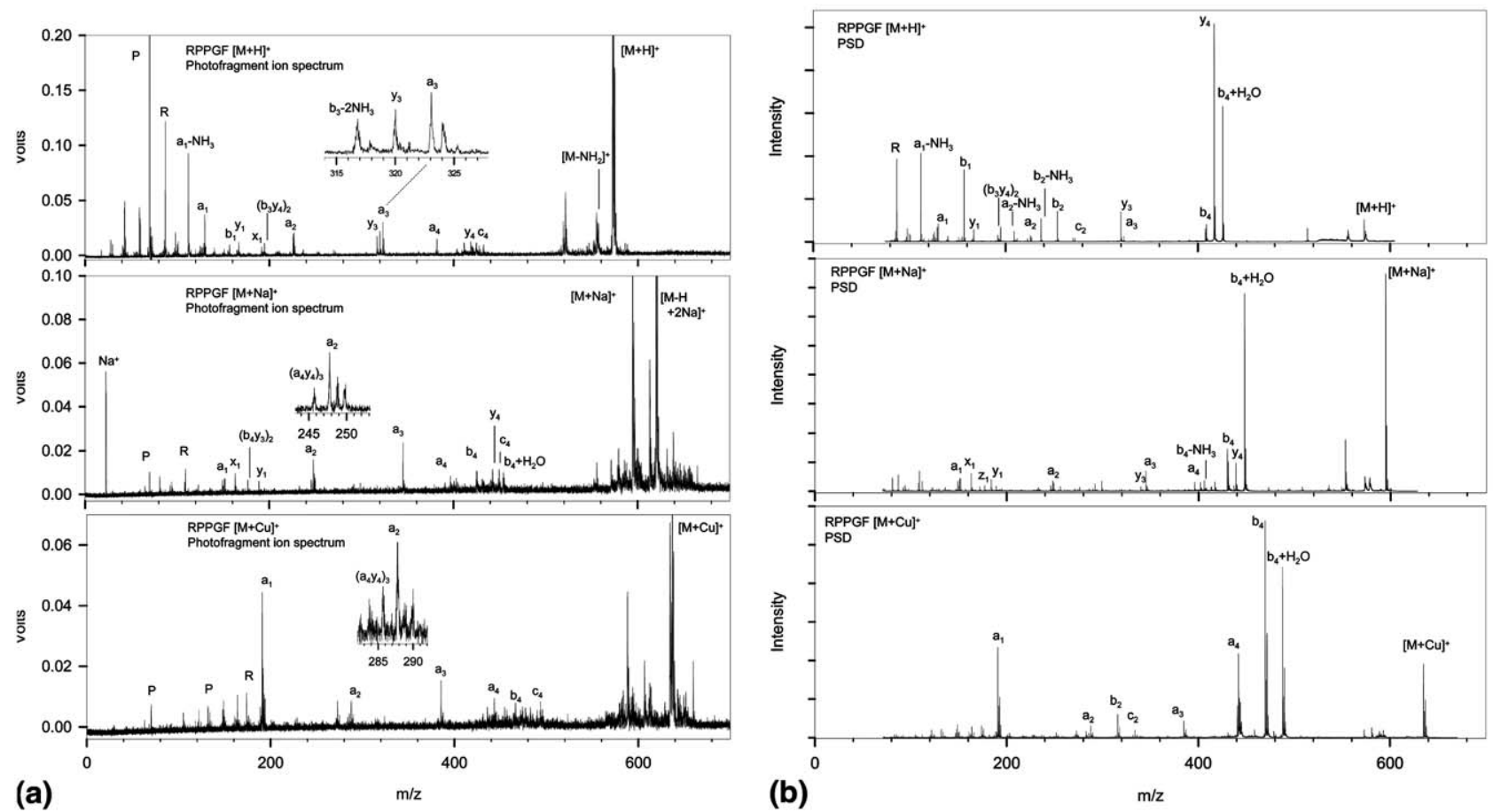

Figure 2. (a) 193-nm photofragment ion spectra of $[\mathrm{M}+\mathrm{H}]^{+},[\mathrm{M}+\mathrm{Na}]^{+}$, and $[\mathrm{M}+\mathrm{Cu}]^{+}$ions of peptide bradykinin fragment 1-5. (b) PSD spectra of $[\mathrm{M}+\mathrm{H}]^{+},[\mathrm{M}+\mathrm{Na}]^{+}$, and $[\mathrm{M}+\mathrm{Cu}]^{+}$ions of peptide bradykinin fragment 1-5 acquired using the Applied Biosystems 4700 proteomics analyzer with medium collision gas pressure and 1-keV collision energy.

solution was mixed 1:1 with $12 \mathrm{mg} / \mathrm{mL}$ CHCA in methanol, and then spotted in $1-\mu \mathrm{L}$ droplets on a stainless steel MALDI plate. Cuprated peptide ions for photodissociation analysis were formed by using the same dried droplet sample preparation on a copper MALDI plate [36]. Cationization with sodium for both experimental techniques and copper for analysis on the Applied Biosystems 4700 instrument were performed by mixing the diluted peptide solution $1: 1$ with $20 \mathrm{mM}$ sodium carbonate or copper sulfate salt and incubating at room temperature for $1 \mathrm{~h}$ before introduction of two parts of the matrix solution.

\section{Results and Discussion}

On the basis of ion mobility-mass spectrometry (IMMS) and molecular dynamics studies, we previously suggested that the structure(s) of protonated $[\mathrm{M}+\mathrm{H}]^{+}$ ions bradykinin fragment 1-5 (BK 1-5; RPPGF) is best described as a charge-solvated, protonated guanidinium ion, and similar structures are also favored for BK 1-6, BK 1-7, BK 1-8; [37] however, such structures may not be applicable for ions with internal energies at or near the dissociation threshold. For example, lowenergy collisional activation (within the ion mobility drift cell) of BK 1-5 [M $+\mathrm{H}]^{+}$ions mobilizes the proton and destabilizes the intra-molecular charge-solvation, and apparently BK $1-n(n=6-8)$ ions behave in a similar manner. Furthermore, intra-molecular charge solvation appears to be less important for BK 2-9 [M +
$\mathrm{H}]^{+}$ions, owing to the absence of the N-terminal arginine and strong intra-molecular interactions (possibly salt-bridges) involving the $\mathrm{C}$-terminal arginine. That is, $[\mathrm{M}+\mathrm{H}]^{+}$ions of peptides such as BK 1-5 with excess internal energy are probably best described in terms of the "mobile proton model". We feel that the series of bradykinin peptides are excellent model systems for studies of the effects of timescale and charge location on the fragmentation chemistry of peptide ions.

Photofragment ion spectra of BK 1-5, BK 1-8, and BK 2-9 are contained in Figures $2 a, 3 a$, and $4 a$, and to illustrate the effects of timescale on fragment ion abundances we also include PSD (composite of MI and CID product ions) spectra for these same ions (Figures $2 b$, $3 \mathrm{~b}$, and $4 \mathrm{~b}$ ). The "prompt" photofragment ion spectra of BK 1-5 $[\mathrm{M}+\mathrm{H}]^{+}$ions is dominated by N-terminal fragment ions, primarily $\mathrm{a}_{\mathrm{i}}$-type ions, and similar fragment ion types are also observed for $[\mathrm{M}+\mathrm{Na}]^{+}$and $[\mathrm{M}$ $+\mathrm{Cu}]^{+}$ions. We interpret the preference for N-terminal fragment ions for $[\mathrm{M}+\mathrm{H}]^{+}$and $[\mathrm{M}+\mathrm{Na}]^{+}$(Figure 2a) as evidence that the charge is located primarily on the $\mathrm{N}$-terminus, probably the arginine side-chain, but lowabundance C-terminal fragment ions [primarily $y_{i}(i=3$ and 4)] suggests that the C-terminus also carries some fraction of the charge. Owing to strong binding of $\mathrm{Cu}^{+}$ by the $\mathrm{N}$-terminal arginine residue, the $[\mathrm{M}+\mathrm{Cu}]^{+}$ion shows an even stronger preference for forming $\mathrm{N}$ terminal fragment ions.

All photofragment ions and PSD fragment ions of BK 1-5 $[\mathrm{M}+\mathrm{Cu}]^{+}$correspond to N-terminal charge 

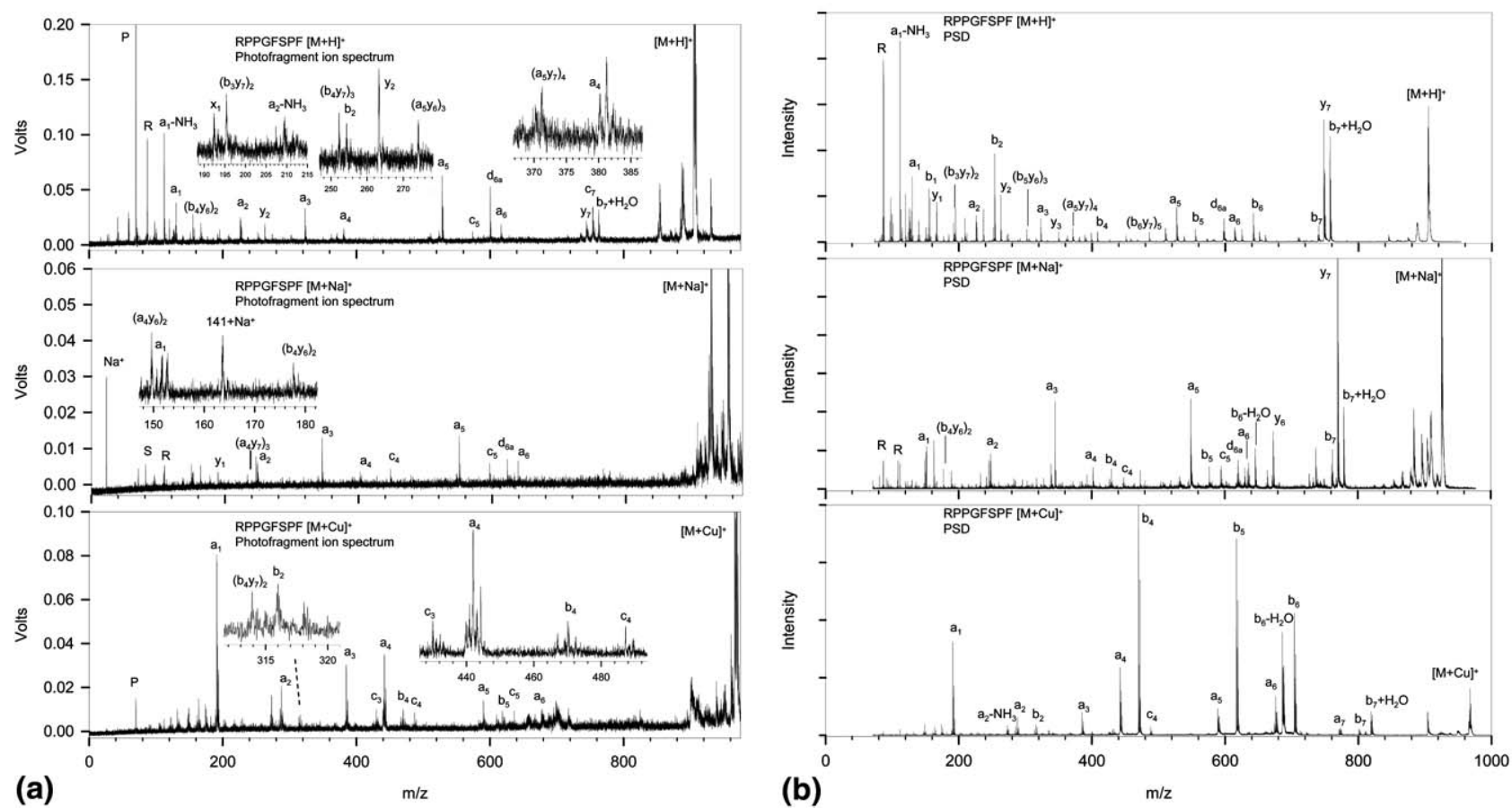

Figure 3. (a) 193-nm Photofragment ion spectra of $[\mathrm{M}+\mathrm{H}]^{+},[\mathrm{M}+\mathrm{Na}]^{+}$, and $[\mathrm{M}+\mathrm{Cu}]^{+}$ions of peptide bradykinin fragment 1-8. (b) PSD spectra of $[\mathrm{M}+\mathrm{H}]^{+},[\mathrm{M}+\mathrm{Na}]^{+}$, and $[\mathrm{M}+\mathrm{Cu}]^{+}$ions of peptide bradykinin fragment 1-8 acquired using the Applied Biosystems 4700 proteomics analyzer with medium collision gas pressure and $1-\mathrm{keV}$ collision energy.
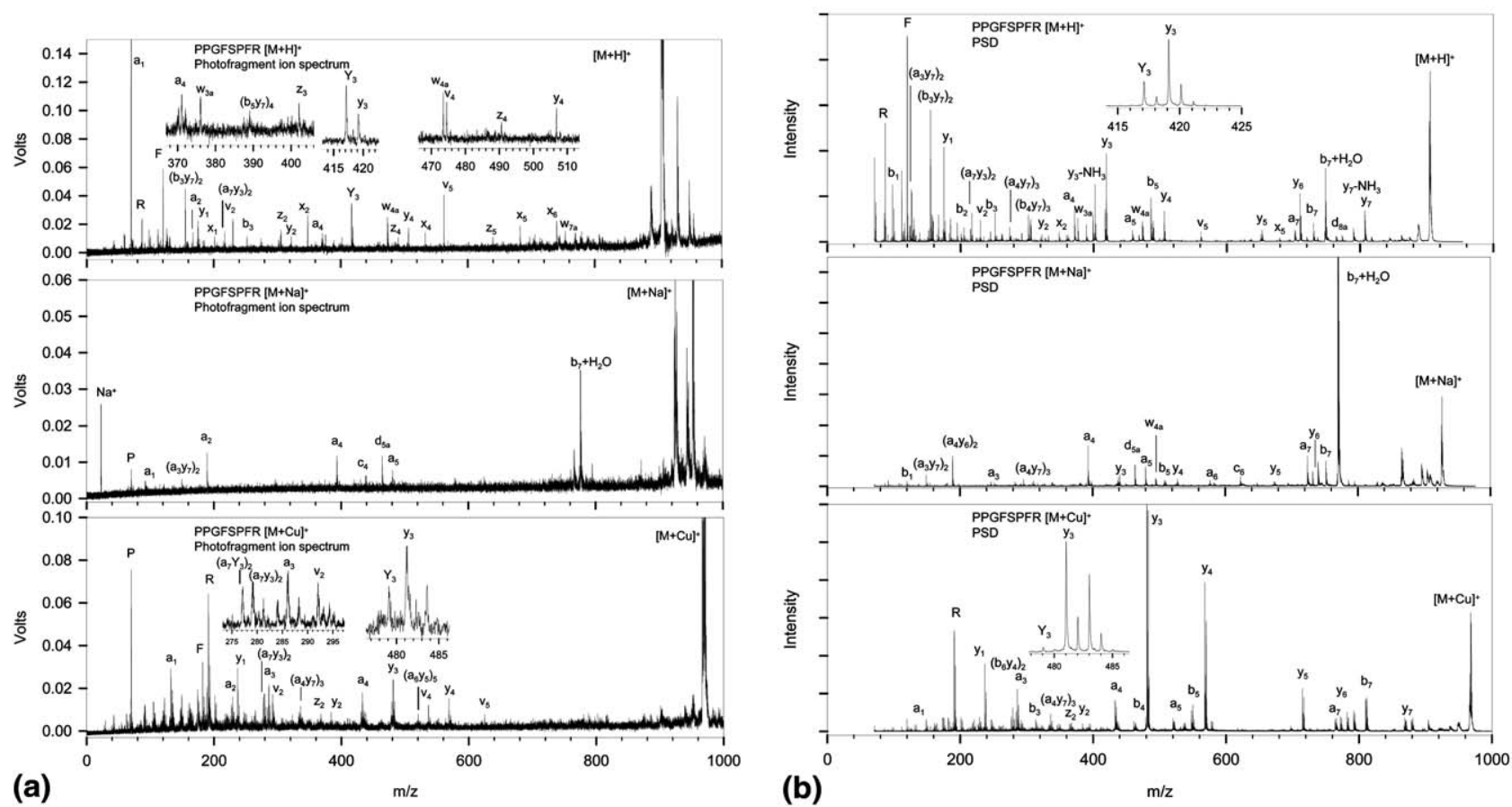

Figure 4. (a) 193-nm Photofragment ion spectra of $[\mathrm{M}+\mathrm{H}]^{+},[\mathrm{M}+\mathrm{Na}]^{+}$, and $[\mathrm{M}+\mathrm{Cu}]^{+}$ions of peptide bradykinin fragment 2-9. (b) PSD spectra of $[\mathrm{M}+\mathrm{H}]^{+},[\mathrm{M}+\mathrm{Na}]^{+}$, and $[\mathrm{M}+\mathrm{Cu}]^{+}$ions of peptide bradykinin fragment 2-9 acquired using the Applied Biosystems 4700 proteomics analyzer with medium collision gas pressure and $1-\mathrm{keV}$ collision energy. 
retention, and apparently bond cleavage reactions at glycine and phenylalanine are favored. For example, the photofragment ion spectrum contains abundant $\mathrm{a}_{4}$, $b_{4}$, and $c_{4}$ ions, which we interpret as evidence that the $\mathrm{N}$-terminal charge-site interacts with the C-terminus. Similar bond cleavage reactions are observed in the PSD spectrum, i.e., $\mathrm{a}_{4}, \mathrm{~b}_{4}, \mathrm{~b}_{4}-\mathrm{NH}_{3}$, and $\mathrm{b}_{4}+\mathrm{H}_{2} \mathrm{O}$. On the basis of computational and IM-MS studies on model phenylalanine containing peptides, we attribute the preferences for $\mathrm{a}_{4}, \mathrm{~b}_{4}$, and $\mathrm{c}_{4}$ fragment ions to additional charge solvation via $\pi$-cation interactions [37]. That is, peptides containing an N-terminal arginine adopt charge-solvated structures where the charge-bearing guanidino group interacts with the backbone carbonyl oxygen atom of the amide group or the phenylalanine side chain.

Photofragment ion spectra of BK 1-6 (Figure S1A, which can be found in the electronic version of this article.) and BK 1-7 (Figure S2A) contain similar $\mathrm{a}_{\mathrm{i}}$-type fragment ions to those observed for BK 1-5. Fewer C-terminal fragment ions are observed for these two peptide ions, and the $\mathrm{C}$-terminal fragment ions that are observed are $\mathrm{x}_{\mathrm{i}}$-type ions rather than the typical $\mathrm{y}_{\mathrm{i}}$ ions. The PSD spectra (Figures S1B and S2B) for $[\mathrm{M}+\mathrm{H}]^{+}$ and $[\mathrm{M}+\mathrm{Na}]^{+}$ions also contain higher relative abundances of $b_{i}$ - and $y_{i}$-type ions than their corresponding photofragment ion spectra, as well as a greater number of small neutral loss ions and internal cleavage products. Various ions formed by cleavage at the serine residue (i.e., $a_{5}, b_{5}, b_{5}+\mathrm{H}_{2} \mathrm{O}$, and $\mathrm{d}_{6 \mathrm{a}}$ for RPPGFS) appear in high abundance in the PSD spectra of [M + $\mathrm{Na}]^{+}$ions, but these ions are absent in the photofragment ion spectra. We attribute differences between PSD and "prompt" photodissociation spectra to effects related to the range of internal energies that are sampled by PSD. This point will be discussed further below.

The "prompt" photodissociation of BK 1-8 (RPPGF$\mathrm{SPF}$ ) $\mathrm{M}+\mathrm{H}]^{+}$(Figure 3a) further illustrates the effect of fragmentation timescale. For example, the "prompt" photofragment ion spectrum contains predominantly $a_{i}$-type ions and an abundant $d_{6 a}$ ion signal, whereas our previously reported PSD photofragment ion spectrum [23] contained abundant $y_{2}, y_{3}$, and $b_{i}$ fragment ions, and secondary fragment ions corresponding to $b_{3}-\mathrm{NH}_{3}, \mathrm{a}_{3}-\mathrm{NH}_{3}, \mathrm{a}_{5}-\mathrm{NH}_{3}, \mathrm{~b}_{6}-\mathrm{NH}_{3},\left(\mathrm{~b}_{5} \mathrm{y}_{7}\right)_{4},\left(\mathrm{~b}_{6} \mathrm{y}_{7}\right)_{5}-\mathrm{H}_{2} \mathrm{O}$, and $\left(\mathrm{b}_{6} \mathrm{y}_{7}\right)_{5}$. The most abundant sequence ions in the PSD spectrum of BK 1-8 $[\mathrm{M}+\mathrm{H}]^{+}$ions (Figure $3 b$ ) are $\mathrm{y}_{7}$ and $\mathrm{b}_{7}+\mathrm{H}_{2} \mathrm{O}$, and the remaining fragment ions consist mainly of $a_{i}$ - and $b_{i}$-type ions with their corresponding ammonia loss ions. The PSD spectrum of BK 1-8 $[\mathrm{M}+\mathrm{Na}]^{+}$ions contains a greater abundance of $\mathrm{a}_{3}$, $\mathrm{a}_{5}$, and $\mathrm{y}_{7}$ ions, which we attribute to strong interactions of $\mathrm{Na}^{+}$with the backbone carbonyl oxygen atoms at phenylalanine and proline residues [38].

Photofragment ion spectra of BK 2-7 (PPGFSP) [M $+\mathrm{H}]^{+}$and $[\mathrm{M}+\mathrm{Na}]^{+}$(Figure S3A) contain a variety of sequence ion types, with both $\mathrm{N}$ - and C-terminal charge carriers, and internal fragment ions, whereas the photofragment ion spectrum of PPGFSP [M +
$\mathrm{Cu}]^{+}$contains almost exclusively N-terminal ions, owing to $\mathrm{Cu}^{+}$ion binding to the N-terminal amine in the absence of arginine or other amino acids with high $\mathrm{Cu}^{+}$ion affinities. Note that the PSD spectra of BK 2-7 (Figure S3B) are similar to those of BK 1-8. Fragmentation to $\mathrm{a}_{\mathrm{i}}$-type ions is enhanced when $\mathrm{Na}^{+}$ is the charge carrier, and $b_{i}$-type ions are preferred for $[\mathrm{M}+\mathrm{Cu}]^{+}$ions. The most abundant PSD fragment ion for $[\mathrm{M}+\mathrm{H}]^{+}$and $[\mathrm{M}+\mathrm{Na}]^{+}$is the $\left[b_{5}+\right.$ $\mathrm{H}_{2} \mathrm{O}^{+}$rearrangement product ion [39], which appears in low abundance in the PSD spectrum of [M + $\mathrm{Cu}]^{+}$.

Comparisons of the fragmentation reactions of BK 1-n ions ( $n=5-8)$ with that of BK 2-9 further illustrates the important role of $\mathrm{N}$-terminal arginine on charge distribution and fragmentation reactions. For example, the "prompt" photofragment ion spectrum of BK 2-9 $[\mathrm{M}+\mathrm{H}]^{+}$ions contains both $\mathrm{N}$-terminal and C-terminal fragment ions (Figure 4a). The C-terminal fragment ions are primarily $\mathrm{x}_{\mathrm{i}}$-type ions, which result from cleavage of peptide backbone carbon-carbon bonds. Other C-terminal charge retention ions include those arising from bond cleavage between a side-chain $\alpha$-carbon and the backbone of a $\mathrm{y}_{\mathrm{i}}$-type ion ( $\mathrm{v}_{\mathrm{i}}$-type ions) and from cleavage between $\alpha$ - and $\beta$-carbons of the side chains of $\mathrm{z}_{\mathrm{i}}$-type ions ( $\mathrm{w}_{\mathrm{ia}}$-type ions). The $\mathrm{Y}_{3}$ ion is also present in greater relative abundance than the $\mathrm{y}_{3}$ ion. The $\mathrm{Y}_{3}$ product may be the result of direct cleavage of the amide bonds without oxazolone ring formation and proton transfer as described by Paizs and Suhai [40], or through $\mathrm{H}_{2}$ elimination from the $\mathrm{y}_{\mathrm{i}}$-type ion. A greater abundance of C-terminal fragment ions is observed in the PSD spectrum of BK 2-9 $[\mathrm{M}+\mathrm{H}]^{+}$and $[\mathrm{M}+\mathrm{Cu}]^{+}$ ions (Figure $4 \mathrm{~b}$ ) relative to that of the N-terminal arginine containing peptides.

It is interesting to note parallels in the chemistry of BK 2-9 $[\mathrm{M}+\mathrm{H}]^{+}$and Lys $^{1}$-BK (KPPGFSPFR) $[\mathrm{M}+$ $\mathrm{H}^{+}$(Figure S4A), both of which yield predominantly C-terminal sequence ions of types $x_{i}, y_{i}$, and $z_{i}$ and product ions formed by side-chain cleavage, i.e., $v_{i}$ and $\mathrm{w}_{\mathrm{ia}}$, owing to the high proton affinity of the C-terminal arginine [30, 41]. Conversely, the photofragment ion spectrum of Lys $^{1}$-BK $[\mathrm{M}+\mathrm{Cu}]^{+}$contains nearly equal abundances of $\mathrm{N}$ - and $\mathrm{C}$-terminal fragment ions, because the $\mathrm{Cu}^{+}$ion affinities for $\mathrm{N}$-terminal lysine and C-terminal arginine are similar (120.4 $\mathrm{kcal} \mathrm{mol}^{-1}$ and $136.1 \mathrm{kcal} \mathrm{mol}^{-1}$, respectively) [30]. Clearly, the fragmentation chemistry of these two peptide ions is governed by charge location, and similar arguments adequately explain a variety of product ions. For example, photofragment ion and PSD spectra of bradykinin (Figure S5A, S5B) contain similar fragmentation products to the spectra of $\mathrm{N}$-terminal arginine containing peptides shown above. A majority of $a_{i}$ ions in the tandem mass spectra of $[\mathrm{M}+\mathrm{Cu}]^{+}$ions is consistent with the charge site being the $\mathrm{N}$-terminus; however, the relative abundance of $y_{i}$ ions indicates that some $\mathrm{Cu}^{+}$ ions also bind to the C-terminal arginine [30]. Note 
also that the $\left[b_{7}+\mathrm{H}_{2} \mathrm{O}\right]^{+}$ion is not observed in the photofragment ion or PSD spectra of BK 2-9 [M + $\mathrm{Cu}]^{+}$ions, because the $\mathrm{Cu}^{+}$ion is bound to the guanidino group of the arginine side-chain, thus the C-terminal amino acid fragment retains the positive charge, leaving $\mathrm{b}_{7}+\mathrm{OH}$ as a neutral species; the product of the rearrangement reaction is observed as the arginine immonium ion at $\mathrm{m} / \mathrm{z} 191$ [42].

Photofragment ion and PSD spectra of BK 1-8 [M $+\mathrm{Cu}]^{+}$ions contain almost exclusively N-terminal fragment ions and detachment of $\mathrm{Cu}^{+}$is not observed under any experimental conditions; both observations support that $\mathrm{Cu}^{+}$is strongly bound to the $\mathrm{N}$-terminal arginine. The "prompt" photofragment ion spectrum of BK 1-8 $[\mathrm{M}+\mathrm{Cu}]^{+}$ions is very similar to that obtained by PSD focusing photodissociation [24], but the relative abundances of $a_{i}$ ions are greater than $b_{i}$ ions in the "prompt" photodissociation, owing to energy dependent rate constants for simple bond cleavage reactions (see below). Relative abundances of $b_{i}$ ions are high in the PSD spectra, especially for $[\mathrm{M}+\mathrm{Cu}]^{+}$ions, which is consistent with the view that $a_{i}$ ions have higher energy requirements than do $b_{i}$ ions, and the energy requirements are increased when the charge is immobilized [7]. The importance of relative energetics on fragmentation chemistry can also be found in other spectra. For example, note that the abundances of non-sequence informative ions, such as loss of small neutral molecules as well as low $\mathrm{m} / \mathrm{z}$ ions, is reduced for $[\mathrm{M}+$ $\mathrm{Cu}]^{+}$ions relative to that observed for $[\mathrm{M}+\mathrm{H}]^{+}$and $[\mathrm{M}+\mathrm{Na}]^{+}$ions for all the peptides examined. For BK 2-9 (Figure 4a and b) and Lys ${ }^{1}$-BK (Figures S4A, S4B), the abundances of $Y_{3}$ ions relative to $y_{3}$ ions are reduced in the spectra of $[\mathrm{M}+\mathrm{Cu}]^{+}$ions, which is also an effect of increased energy of fragmentation for peptide ions containing an immobilized charge carrier. The longer reaction times available for fragmentation by PSD relative to "prompt" photofragmentation favor the lower energy reaction channels, i.e., formation of $y_{i}$ ions.

The fragmentation reactions of the peptide ions examined in this study can all be rationalized in terms of charge location and relative energetics for various bond cleavage reactions. In no case do we find evidence to support an ion "shattering" mechanism [43], nonergodic fragmentation reactions [25, 26], or charge-remote fragmentation [44]. That is, the fragmentation reactions, including significant differences between PSD and "prompt" photodissociation, can be explained within the framework of quasiequilibrium theory (QET). For example, Figure 5 contains a generic Wahrhaftig plot which generalizes peptide fragmentation, where $\rho(E)$ represents hypothetical internal energy distribution of ions formed by MALDI and $k(E)$ represents the energy dependent rate constant for specific dissociation channels: A, B, and $\mathbf{C}$ represent reactions channels having very different energy requirements, indicated by different

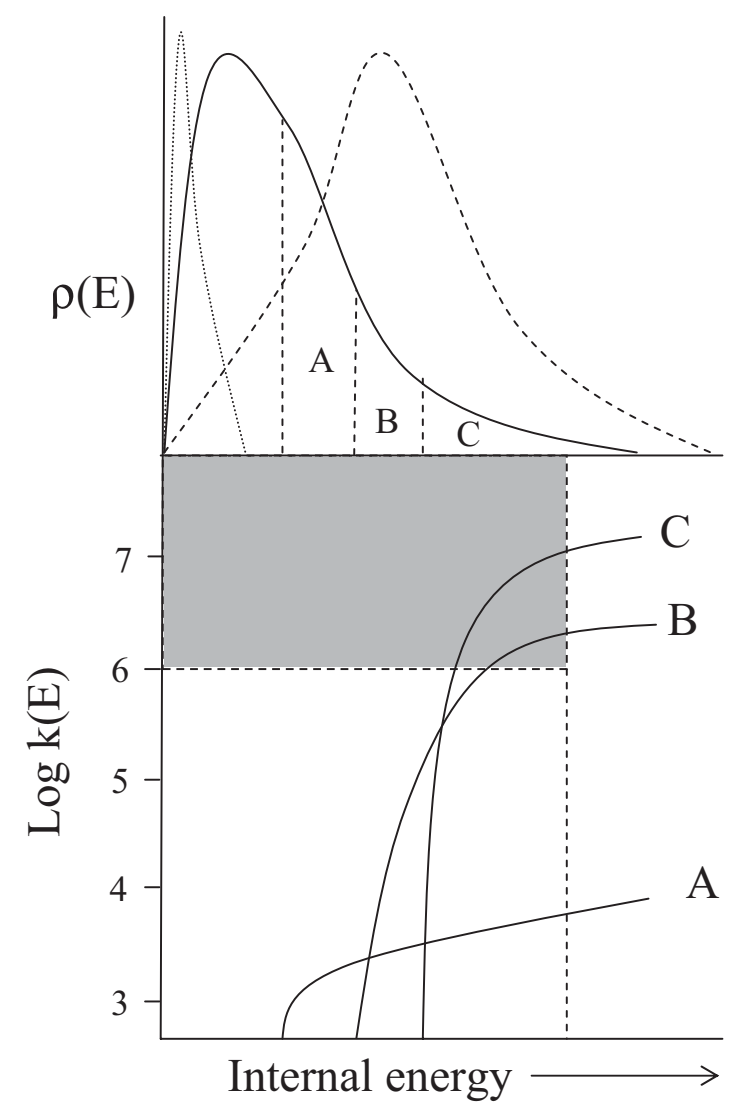

Figure 5. Generic Wahrhaftig diagram for the kinetics of peptide ion fragmentation. The dotted line in the $\rho(\mathrm{E})$ plot represents ions formed with threshold ionization energy, the solid line represents ions formed with laser fluence slightly above threshold, and the dashed line represents ions formed at high laser fluence.

thresholds, and entropic requirement as indicated by the different shapes for the $\mathrm{k}(\mathrm{E})$ versus $\mathrm{E}$ plots. For example, rearrangement reactions that yield products such as $\left[b_{i}+\mathrm{H}_{2} \mathrm{O}\right]^{+}$are represented by $\mathbf{A}$, dissociation reactions subject to rate-determining steps, such as $\mathrm{H}^{+}$transfer (products such as $\mathrm{b}_{\mathrm{i}}$ and $\mathrm{y}_{\mathrm{i}}$ ) are represented by $\mathbf{B}$, and simple bond cleavage reactions $\left(\mathrm{a}_{\mathrm{i}}, \mathrm{x}_{\mathrm{i}}\right.$, and side-chain cleavage reactions) are represented by $\mathrm{C}$.

PSD spectra are composed of fragment ions formed over a broad range of $\mathrm{k}(\mathrm{E})$ values, i.e., $10^{4}$ to $10^{6} \mathrm{~s}^{-1}$, and consequently these spectra contain a large variety of fragment ion types that include A, B, and low abundances of $\mathbf{C}$. On the other hand, 193-nm photofragment ion spectra contain higher abundances of $\mathbf{B}$ and C-type fragment ions, because the internal energies of MALDI generated ions is dramatically increased by absorption of a highly energetic $193-\mathrm{nm}(6.43 \mathrm{eV})$ photon. There is an even greater enhancement of C-type fragment ions in the "prompt" photofragment ion spectrum because only ions with sufficient energy to fragment on the microsecond timescale are sampled by this experiment. On this timescale, formation of $\left[b_{i}+\mathrm{H}_{2} \mathrm{O}\right]^{+}$product ions is kinetically prohibited, and the abundances of $b_{i} / y_{i}$ 
fragment ions are diminished relative to the higher energy reactions channels to form $a_{i}, c_{i}, x_{i}$, and $z_{i}$ fragment ions.

\section{Conclusions}

The fragmentation spectra of the bradykinin analogues demonstrate the utility of "prompt" 193-nm photodissociation for fundamental studies of peptide fragmentation. The limited fragmentation timescale $(<1 \mu \mathrm{s})$ reduces contributions from non-sequence informative, fragment ions, esp. loss of small neutral molecules and internal cleavage products. Additionally, compared to PSD focusing photodissociation experiments that sample fragment ions formed over $\sim 10 \mu \mathrm{s}$, lower relative abundances of amide bond cleavage products were observed. The most commonly observed promptly-formed fragment ions of peptides activated by 193-nm photons include $\mathrm{a}_{\mathrm{i}}$ - and $\mathrm{x}_{\mathrm{i}}$-type ions, the result of backbone carbon-carbon bond cleavage. Such fragmentation reactions are readily understood on the basis of quasi-equilibrium theory (QET) and we do not find any reasons to invoke a "shattering" mechanism for dissociation of higher energy ions [43].

As we have noted in previous work, the fragmentation reactions of $[\mathrm{M}+\mathrm{H}]^{+}$and $[\mathrm{M}+\mathrm{Na}]^{+}$ions differ significantly from that of $[\mathrm{M}+\mathrm{Cu}]^{+}$ions, owing to the strong binding of $\mathrm{Cu}^{+}$to N-bases [30, 31]. For the most part; however, these differences in fragmentation reactions are not observed in the "prompt" photofragment ion spectra. That is, for N-terminal charge carriers, i.e., peptides with $\mathrm{R}, \mathrm{K}$, or $\mathrm{H}$ at the $\mathrm{N}$-terminus, the photofragment ion spectra for $[\mathrm{M}+\mathrm{H}]^{+},[\mathrm{M}+\mathrm{Na}]^{+}$, and $[\mathrm{M}+\mathrm{Cu}]^{+}$contain almost exclusively $\mathrm{a}_{\mathrm{i}}$ type ions. Peptides that contain a C-terminal charge carrier dissociate to yield both $\mathrm{N}$-terminal charge fragments, owing to the basic $\mathrm{N}$-terminus, as well as basic C-terminal fragment ions.

\section{Acknowledgments}

The authors thank the Robert A. Welch Foundation for continued support of metal ion chemistry studies, the United States Department of Energy, Division of Chemical Science for support of photodissociation studies, and The National Science Foundation Major Research Instruments Grant Program for funding the development of advanced time-of-flight instrumentation.

\section{References}

1. Karas, M.; Bachmann, D.; Bahr, U.; Hillencamp, F. Matrix-Assisted Ultraviolet Laser Desorption of Nonvolatile Compounds. Int. J. Mass Spectrom. Ion Processes 1987, 78, 53-81.

2. Tanaka, K.; Waki, H.; Ido, Y.; Akita, S.; Yoshida, Y.; Yoshida, T. Protein and Polymer Analyses up to $m / z 100,000$ by Laser Ionization Time-ofFlight Mass Spectrometry. Rapid Commun. Mass Spectrom. 1988, 2, 151-153.

3. Fenn, J. B.; Mann, M.; Meng, C. K.; Wong, S. F.; Whitehouse, C. M. Electrospray Ionization for Mass Spectrometry of Large Biomolecules. Science 1989, 246, 64-71.
4. Shevchenko, A.; Jenson, O. N.; Podtelejnikov, A. V.; Sagliocco, F.; Wilm, M.; Vorm, O.; Mortensen, P.; Shevchenko, A.; Boucherie, H.; Mann, M. Linking Genome and Proteome by Mass Spectrometry: Large-Scale Identification of Yeast Proteins from Two Dimensional Gels. Proc. Natl. Acad. Sci. U.S.A. 1996, 93, 14440-14445.

5. Henzel, W. J.; Watanabe, C.; Stults, J. T. Protein Identification: The Origins of Peptide Mass Fingerprinting. J. Am. Soc. Mass Spectrom. 2003, 14, 931-942.

6. Yergey, A. L.; Coorssen, J. R.; Backlund, P. S.; Blank, P. S.; Humphrey, G. A.; Zimmerberg, J.; Cambpell, J. M.; Vestal, M. L. De Novo Sequencing of Peptides Using MALDI/TOF-TOF. J. Am. Soc. Mass Spectrom. 2002, 13, 784-791.

7. Dongré, A. R.; Jones, J. L.; Somogyi, A.; Wysocki, V. Influence of Peptide Composition, Gas-Phase Basicity, and Chemical Modification on Fragmentation Efficiency: Evidence for the Mobile Proton Model. J. Am. Chem. Soc. 1996, 118, 8365-8374.

8. Meroueh, S. O.; Wang, Y.; Hase, W. L. Direct Dynamics Simulations of Collision- and Surface-Induced Dissociation of N-Protonated Glycine. Shattering Fragmentation. J. Phys. Chem. A 2002, 106, 9983-9992.

9. Zhao, H.; Adams, J. Mechanisms of Fragmentation of Cationic Peptide Ions. Int. J. Mass Spectrom. Ion Processes 1993, 125, 195-205.

10. Baer, T.; Hase, W. L. In Unimolecular Reaction Dynamics: Theory and Experiments; Oxford University Press: New York, 1996; p 202.

11. Roepstorff, P.; Fohlmann, J. Proposal for a Common Nomenclature for Sequence Ions in Mass Spectra of Peptides. Biomed. Mass Spectrom. 1984, 11,601 .

12. Biemann, K. Nomenclature for Peptide Fragment Ions (Positive Ions). Methods Enzymol. 1990, 193, 886-887.

13. Tecklenburg, R. E.; Miller, M. N.; Russell, D. H. Laser Ion Beam Photodissociation Studies of Model Amino Acids and Peptides. J. Am. Chem. Soc. 1989, 111, 1161-1171.

14. Gabelica, V.; De Pauw, E. Internal Energy and Fragmentation of Ions Produced in Electrospray Sources. Mass Spectrom. Rev. 2005, 24, 566587.

15. Johnson, R. S.; Martin, S. A.; Biemann, K. Collision-Induced Fragmentation of $[\mathrm{M}+\mathrm{H}]^{+}$Ions of Peptides. Side Chain Specific Sequence Ions. Int. J. Mass Spectrom. Ion Processes 1988, 86, 137-154.

16. McLafferty, F. W.; Turacek, F. Theory of Unimolecular Ion Decompositions. In Interpretation of Mass Spectra, 4th ed.; University Science Books: Sausalito, CA, 1993; pp 115-117.

17. Bradley, C. D.; Curtis, J. M.; Derrick, P. J. Collisional Activation of Large Ions. Energy Losses and an Impulsive Collision Theory of Energy Transfer. J. Chem. Soc. Faraday Trans. 1994, 90, 239-247.

18. Preiss, J. W.; Setlow, R. Spectra of Some Amino Acids, Peptides, Nucleic Acids, and Protein in the Vacuum Ultraviolet. J. Chem. Phys. 1956, 25, 138-141.

19. Li, L.; Lubman, D. L. Ultraviolet-Visible Absorption Spectra of Biological Molecules in the Gas Phase Using Pulsed Laser-Induced Volatilization Enhancement in a Diode Array Spectrophotometer. Anal. Chem. 1987, 59(20), 2538-2541.

20. Lakowicz, J. R. Protein Fluorescence. In Principles of Fluorescence Spectroscopy; Plenum Press: New York, NY, 1983; pp 341-381.

21. Barbacci, D. C. Photodissociation of Peptide Ions in a Matrix-Assisted Laser Desorption Ionization Reflectron Time-of-Flight Mass Spectrometer; Ph.D. Thesis, Texas A and M University, 2000.

22. Barbacci, D. C.; Russell, D. H. Sequence and Side-Chain Specific Photofragment $(193 \mathrm{~nm})$ Ions from Protonated Substance-P by MatrixAssisted Laser Desorption Ionization Time-of-Flight Mass Spectrometry. J. Am. Soc. Mass Spectrom. 1999, 10, 1038-1040.

23. Hettick, J. M.; McCurdy, D. L.; Barbacci, D. C.; Russell, D. H. Optimization of Sample Preparation for Peptide Sequencing by MALDI-TOF Photofragment Mass Spectrometry. Anal. Chem. 2001, 73, 5378-5386.

24. Morgan, J. W.; Hettick, J. M.; Russell, D. H. Peptide Sequencing by MALDI 193-nm Photodissociation TOF MS. Methods Enzym. 2005, 402, $186-209$.

25. Thompson, M. S.; Cui, W.; Reilly, J. P. Fragmentation of Singly Charged Peptide Ions by Photodissociation at $1=157 \mathrm{~nm}$. Angew. Chem. Int. Ed. 43, 2004, 4791-4794.

26. Cui, W.; Thompson, M. S.; Reilly, J. P. Pathways of Peptide Ion Fragmentation Induced by Vacuum Ultraviolet Light. J. Am. Soc. Mass Spectrom. 2005, 16, 1384-1398.

27. Tomer, K. B.; Deterding, L. J.; Guenat, C. Collisionally Activated Dissociation Spectra of Sodiated Peptides and Peptide Amides. Biol. Mass Spectrom. 1991, 20, 121-129.

28. Cerda, B. A.; Cornett, L.; Wesdemiotis, C. Probing the Interaction of Alkali and Transition Metal Ions with Bradykinin and its des-Arginine Derivatives via Matrix-Assisted Laser Desorption/Ionization and Postsource Decay Mass Spectrometry Int. J. Mass Spectrom. 1999, 193 (2/3), 205-226.

29. Teesch, L. M.; Adams, J. Fragmentations of Gas-Phase Complexes Between Alkali Metal Ions and Peptides: Metal Ion Binding to Carbonyl Oxygens and Other Neutral Functional Groups. J. Am. Chem. Soc. 1991, $113,812-820$

30. Bluhm, B. K.; Shields, S. J.; Bayse, C. A.; Hall, M. B.; Russell, D. H. Determination of Copper Binding Sites in Peptides Containing Basic Residues: A Combined Experimental and Theoretical Study. Int. J. Mass Spectrom. 2001, 204, 31-46.

31. Shields, S. J.; Bluhm, B. K.; Russell, D. H. Fragmentation Chemistry of $[\mathrm{M}+\mathrm{Cu}]^{+}$Peptide Ions Containing an N-terminal Arginine. J. Am. Soc. Mass Spectrom. 2000, 11, 626-638. 
32. Spengler, B.; Kirsch, D.; Kaufmann, R. Fundamental Aspects of PostSource Decay in Matrix-Assisted Laser Desorption Mass Spectrometry. 1. Residual Gas Effects. J. Phys. Chem. 1992, 96, 9678-9684

33. Gimon-Kinsel, M. E. Kinsel, G. R.; Edmondson, R. D.; Russell, D. H. Photodissociation of High Molecular Weight Peptides and Proteins in a Two-Stage Linear Time-of-Flight Mass Spectrometer. J. Am. Soc. Mass Spectrom. 1995, 6, 578-587.

34. Morgan, J. W.; Russell, D. H. Matrix-Assisted Laser Desorption/ Ionization Tandem Time-of-Flight Mass Spectrometer for Photodissociation of Peptide Ions. Rev. Sci. Inst., unpublished.

35. Macht, M.; Asperger, A.; Deininger, S. Comparison of Laser-Induced Dissociation and High-Energy Collision-Induced Dissociation Using Matrix-Assisted Laser Desorption/Ionization Tandem Time-of-Flight (MALDI-TOF/TOF) for Peptide and Protein Identification. Rapid Commun. Mass Spectrom. 2004, 18, 2093-2105.

36. Shields, S. J.; Bluhm, B. K.; Russell, D. H. Novel Method for $[\mathrm{M}+\mathrm{Cu}]^{+}$ Ion Formation by Matrix-Assisted Laser Desorption Ionization. Int. J. Mass Spectrom. 1999, 182/183, 185-189.

37. Sawyer, H. A.; Marini, J. T.; Stone, E. G.; Ruotolo, B. T.; Gillig, K. J.; Russell, D. H. The Structure of Gas-Phase Bradykinin Fragment 1-5 (RRPGF) Ions: An Ion Mobility Spectrometry and H/D Exchange Ion-Molecule Reaction Chemistry Study. J. Am. Soc. Mass Spectrom. 2005, 16, 893-905.
38. Grese, R. P.; Cerny, R. L.; Gross, M. L. Metal Ion-Peptide Interactions in the Gas Phase: A Tandem Mass Spectrometry Study of Alkali Metal Cationized Peptides. J. Am. Chem. Soc. 1989, 111, 2835-2842.

39. Thorne, G. C.: Ballard, K. D. Gaskell, S. J. Metastable Decomposition of Peptide $[\mathrm{M}+\mathrm{H}]^{+}$Ions via Rearrangement Involving Loss of the C-Terminal Amino Acid Residue. J. Am. Soc. Mass Spectrom. 1990, 1, 249-257.

40. Paizs, B.; Suhai, S.; Towards Understanding the Tandem Mass Spectra of Protonated Oligopeptides. 1. Mechanism of Amide Bond Cleavage. J. Am. Soc. Mass Spectrom. 2004, 15, 103-113.

41. Lei, Q. P.; Amster, I. J. The Reactions of Ground State $\mathrm{Cu}^{+}$and $\mathrm{Fe}^{+}$with the 20 Common Amino Acids. J. Am. Soc. Mass Spectrom. 1996, 7, 722-730.

42. Fang, S.; Takao, T.; Satomi, Y.; Mo, W.; Shimonishi, Y. Novel Rearrangement Ions Observed for Protonated Peptides Via Metastable Decomposition in Matrix-Assisted Laser Desorption/Ionization Time-of-Flight Mass Spectrometry. J. Am. Soc. Mass Spectrom. 2000, 11, 345-351.

43. Laskin, J.; Bailey, T. H.; Futrell, J. H. Shattering of Peptide Ions on Self-Assembled Monolayer Surfaces. J. Am. Chem. Soc. 2003, 125, 16251632.

44. Cheng, C.; Gross, M. L. Applications and Mechanisms of ChargeRemote Fragmentation. Mass Spectrom. Rev. 2000, 19, 398-420. 